\title{
Evolution of global inequality in human well-being: a sensitivity analysis
}

\section{Vanesa Jordá*, Carmen Trueba and José María Sarabia}

Department of Economics, University of Cantabria,

Av. los Castros SN,

Santander 39003, Spain

Fax: +34 942201603

Email: jordav@unican.es

Email: carmen.trueba@unican.es

Email: jose.sarabia@unican.es

${ }^{*}$ Corresponding author

\begin{abstract}
In this paper, we study global inequality in well-being taking as a theoretical benchmark the Human Development Index (HDI), which comprises variables of income, health and education. We use a two-step methodology that involves the construction of a composite index in the first step on which inequality measures are computed. The use of these measures requires making choices on the standardisation of the variables and their weights, the rate of substitution between dimensions and the degree of inequality aversion in the society. We investigate the impact of these choices on the evolution of unweighted inequality over the period 1980-2011. We find the robust result that global inequality in human well-being decreased over the last 30 years.
\end{abstract}

Keywords: HDI; Human Development Index; well-being; multidimensional inequality; generalised entropy.

Reference to this paper should be made as follows: Jordá, V., Trueba, C. and Sarabia, J.M. (2015) 'Evolution of global inequality in human well-being: a sensitivity analysis', Int. J. Computational Economics and Econometrics, Vol. 5, No. 1, pp.108-125.

Biographical notes: Vanesa Jordá is $\mathrm{PhD}$ in Economics from the University of the Basque Country, the University of Oviedo and the University of Cantabria (2014). Her main lines of research are multidimensional well-being distribution, inequality and convergence of national levels of quality of life.

Carmen Trueba, BA, in Economics at the University of Cantabria (2007), MA in Economics at the University of País Vasco, University of Cantabria and University of Oviedo (2008) and $\mathrm{PhD}$ in Economics at the University of Cantabria (2011). She is an Assistant Lecturer in the Department of Economics at the University of Cantabria. Her mains fields on interest are human development measurement, distribution theory with applications in Economics and informetrics, fields in which she has published several articles in prestigious national and international journals.

José María Sarabia is Professor of Quantitative Methods in Business and Economics in the Department of Economics at the University of Cantabria. His main fields of interest are: economic inequality, distribution theory 


\begin{abstract}
and multivariate analysis with applications to risk analysis, finance and informetrics. He is Associate Editor in several journals including the Journal of Banking and Finance, Statistical Methodology and Journal of Statistical Distributions and Applications.
\end{abstract}

This is a revised and expanded version of the paper entitled 'Assessing global inequality in well-being using generalized entropy measures' presented at International Conference on Applied Economics (ICAE), Istanbul, 27-29 June, 2013.

\title{
1 Introduction
}

The interest of academics in assessing country levels of well-being has shifted from an income perspective to a multidimensional conception of this process. Quality of life is characterised by an intrinsic multidimensional nature, which is partially ignored by economic variables (see e.g., Sen, 1988, 1989, 1999). As a consequence, other factors need to be taken into account to evaluate this phenomenon effectively. This line of argumentation has gained prominence among academics, leading to many attempts to synthesise different aspects of human well-being in a composite index, which offers a more comprehensive panorama than per-capita income alone.

The conception of well-being as a multidimensional process has brought to the fore the question of whether levels of quality of life is converging across countries. In contrast to the pattern shown by economic variables, non-income dimensions seem to be characterised by a convergence process (Hobin and Franses, 2001; Neumayer, 2003; Kenny, 2005; McGillivray and Markova, 2010). The different trends exhibited by the individual dimensions of quality of life make it difficult to draw integral conclusions about the evolution of well-being inequality.

In this context, multidimensional inequality measures are useful tools to study the evolution of disparities in well-being. Along this line, two different approaches have been identified. The normative approach derives the inequality measures from a battery of axioms that should be ideally satisfied. On the other hand, the two-step procedure computes first a composite index and then calculates unidimensional inequality measures of that indicator (Maasoumi, 1986). These two approaches have been considered as completely different in essence and the adequacy of the last method has been questioned (see Weymark, 2006). However, the two-step measures have been recently embedded in the normative framework by Bosmans et al. (2013), who decompose multidimensional inequality in two components: inefficiency and inequity. Inefficiency is associated to the loss of welfare owing to the absence of exchanges that would be beneficial for all individuals in the society. Inequity evaluates the differences in the levels of well-being and corresponds to the two-step measures, hence being ideal instruments for the analysis of convergence.

A number of studies have investigated whether the gap between developed and developing countries narrowed in terms of well-being (see, e.g., Konya and Guisan (2008) and Jordá and Sarabia (2014)). While the main conclusion is that levels of quality of life converged over the last decades, the results seem to be sensitive to different indicators of well-being and the inequality measures considered (McGillivray and Pillarisetti, 2004). Quality of life indicators differ in the variables that comprise each 
index, which are transformed and weighted differently in each case. The assumed substitutability degree across dimensions has also a deep influence not only on the assessment of disparities, but also in the meaning of the indicators and the implicit trade-offs between dimensions. Up to now, there is no consensus about the optimal weighting structure, standardisation procedure and the degree of substitution that lead a universal picture of the reality of the country in terms of well-being.

This paper investigates the role of these choices in the evolution of disparities in quality of life using two-step measures. This question was partially addressed by Martínez (2012), who computed several inequality measures for the old and the new versions of the HDI, which mainly differ in the assumed degree of substitution. Jordá et al. (2013) calculated inequality measures for different elasticities of substitution between dimensions, concluding a convergence pattern in well-being under all of scenarios considered. We propose to extend these analyses computing inequality measures for a large number of combinations of the degree of substitution and the inequality aversion parameter. The sensitivity of the results to different weighting schemes is also studied and the impact of the logarithmic transformation of the income component is also investigated. ${ }^{1}$ The results suggest that the gap between developed and developing countries unambiguously narrowed over that last three decades.

The rest of the paper is organised as follows. Section 2 describes the main characteristics of the HDI as an indicator of well-being. The construction of the multidimensional generalised entropy measures is detailed in Section 3. In Section 4, we study, as a preliminary analysis, the shape of the cross-country distribution of well-being under a number of scenarios. Thereafter, we perform a sensitivity analysis of the evolution of unweighted inequality to different normative choices. Finally, Section 5 presents the main conclusions of the study.

\section{The Human Development Index}

The development of the HDI responds to a long-standing tradition of the sole use of percapita GDP as an indicator of well-being. In this context, the HDI emerges as an indicator conceived to provide more comprehensive information than income per se.

The HDI was introduced in the first Human Development Report elaborated by the United Nations Development Programme (UNDP) in 1990. It was presented as a composite index that attempted to quantify well-being levels of the countries. Human development is conceived as a process of enlarging the opportunities of the human being, considering as the three most essential aspects "to enjoy a long and healthy life, to acquire knowledge and to have access to resources needed for a decent standard of living" (UNDP, 1990). According to this definition, the HDI measures a country's achievement according to three basic dimensions: health, education and income.

Before 2010, the HDI was constructed using the arithmetic mean. The traditional simple average was not considered representative since the components of the index are regarded as perfect substitutes, thus implying that the marginal rate of substitution is constant. This assumption can lead to incongruent results, in the sense that the maximisation of the HDI in a society may lead to corner solutions, thus promoting one dimension and disregarding others (Klugman et al., 2011). The 2010 Human Development Report stated that the geometric mean would replace the arithmetic mean in the construction of the index (UNDP, 2010). 


$$
\mathrm{HDI}=I_{\text {Health }}^{1 / 3} \cdot I_{\text {Education }}^{1 / 3} \cdot I_{\text {Income }}^{1 / 3} \cdot
$$

The formula introduced in 2010 marks a conceptual change concerning the relationship between the three components, reducing the rate of substitution among dimensions and introducing some degree of complementarity. ${ }^{2}$

Intermediate indices comprise country-level data on income $\left(y_{i}\right)$, life expectancy $\left(h_{i}\right)$ and two variables for education - mean years of schooling $\left(e^{1}{ }_{i}\right)$ and expected years of schooling $\left(e^{2}{ }_{i}\right)$ - which reflect achievements in each dimension with respect to the subsistence level and the historical maximum value. The minimum and maximum values are set to transform the original variables into indices ranged from 0 to 1 . Intermediate indices for health, education and income are expressed, respectively, as follows:

$$
\begin{aligned}
& I_{\text {Health }}=\frac{h_{i}-h_{\text {min }}}{h_{\text {max }}-h_{\text {min }}}, \\
& I_{\text {Education }}=\left[\left(\frac{e_{i}^{1}-e_{\min }^{1}}{e_{\max }^{1}-e_{\min }^{1}}\right) \cdot\left(\frac{e_{i}^{2}-e_{\min }^{2}}{e_{\text {max }}^{2}-e_{\text {min }}^{2}}\right)\right]^{1 / 2} \text { and } \\
& I_{\text {Income }}=\frac{\ln \left(y_{i}\right)-\ln \left(y_{\min }\right)}{\ln \left(y_{\max }\right)-\ln \left(y_{\min }\right)} .
\end{aligned}
$$

Subscript min refers to the subsistence level. It is set to zero for educational variables given that societies would survive without education and $100 \$$ for income. For the health index, 20 years is the minimum life that ensures the reproduction of societies. Conversely, subscript max denotes the maximum values observed. In the case of educational variables $e^{1}$ and $e^{2}$, respectively, the maximum corresponds to Czech Republic in 2005 with 13.1 and 18 years, which is achieved by several developed countries. The maximum value observed for income is $107721 \$$ (per-capita GNI for Qatar in 2011), while 85 years is the highest life expectancy observed, which corresponds to Japan in 2011. On the other hand, the logarithmic transformation of income responds to the fact that it is a mean to achieve well-being. Then, this transformation would account for the diminishing returns of income to human development.

\section{Methodology}

Let $x_{i k}, k=1,2, \ldots, K ; i=1, \ldots, N$ be the amount of the attribute $k$ in the country $i$. These values are included in the $N \times K$ distribution matrix $\mathbf{X}=\left\{x_{i k}\right\}$ whose rows are denoted as $X_{i .}$ and columns are denoted as $X_{. k}$. To assess multidimensional well-being inequality, we use the two-step procedure proposed by Maasoumi (1986). In the first stage, the dimensions are aggregated for each country using a summary measure denoted by $s_{i}=h\left(X_{i}\right)$. According to Maasoumi (1986), if $s_{i}$ is seen as the 'observer's' evaluation of individual welfare (in this case, the level of welfare in a particular country), such index should be distributed as similar as possible to the distribution of $X_{. k}$. To determine the optimal indicator, he relies on information theory to find the index that least diverges from the distributional 'information' enclosed in $X_{. k}$. Minimising the Kullback-Leibler 
distance leads the optimal $s_{i}\left(X_{i}\right)$ indicator, characterised by a generalised mean of order $-\beta$ :

$$
S_{i} \propto\left(\sum_{k=1}^{K} \delta_{k}\left(x_{i k}\right)^{-\beta}\right)^{-1 / \beta} \quad i=1, \ldots, N .
$$

According to Maasoumi and Nikelsbourg (1988), the judgement values of the analyst are reflected by the choice of the weights and the level of substitution. The coefficients $\delta_{k}$, $k=1, \ldots, K$, are the weights assigned to each dimension in the construction of the index, which are constrained to sum to one. The selection of the weights plays an important role in the construction of $s_{i}$, and hence in our evaluation of the level of quality of life. There are three different approaches to define a weighting scheme (Decancq and Lugo, 2013): data-driven techniques, normative choices and hybrid approaches. In the first case, these parameters are determined by the data enclosed in the distribution matrix. The main drawback of this approach is that no normative insights are used to derive them. In the other extreme, the normative approach relies only on value judgements. Since the conceptualisation of 'what is good life' can vary from one country to another, we could be evaluating well-being using weights that contradict the social preferences in some countries. Finally, hybrid techniques combine both approaches, giving some flexibility since they are based on the opinions of the citizens. However, limitations in the availability of the data make it difficult to implement this technique for a wide range of countries.

The HDI applies an equal weighting scheme, hence setting this parameter to $1 / 3, \forall k$. While this structure seems to be rather arbitrary, some authors argue that there is no reason to weigh more on one dimension than another (Haq, 2003). On the other hand, the equal weighting scheme seems to be supported by the data (see, e.g., Nguefack-Tsague et al. (2011)) and it is consistent with expert's opinion (Chowdhury and Squire, 2006). It is beyond the scope of this paper to justify the weighting structure of the HDI. This scheme has been used by the UNDP throughout the history of this indicator, justified by its simplicity, transparency and the argument that all dimensions are equally important (UNDP, 1990). However, since this choice seems to be controversial, we also analyse its influence performing a sensitivity analysis on the weights in the next section.

The role played by the $\beta$ parameter is related to the elasticity of substitution between dimensions. In particular, this parameter is expressed as a function of the elasticity of substitution $(\sigma)$ by $\beta=(1 / \sigma)-1$. The well-being index $s_{i}$ is defined for any real value of $\beta \in[-\infty, \infty]$, but implicitly assuming different relationships between dimensions and the level of well-being. As limiting cases, we have $\beta=-1$ and then $\sigma$ tends to infinity, implying that the dimensions are treated as perfect substitutes. This specification would lead to an $s_{i}$ index represented by the arithmetic mean and hence it would be associated with the old version of the HDI.

$$
s_{i}=\sum_{k=1}^{K} \delta_{k} x_{i k} .
$$

This assumption would imply that the loss in well-being owing to one year less of life expectancy could be compensated by higher levels of income or could be substituted by high educational standards. In contrast, if the value of the parameter is set to $0, s_{i}$ is a 
function of Cobb-Douglas type. This structure imposes some degree of substitution and complementarity, thus favouring internal solutions, which promote equal performance across dimensions. This case corresponds to new HDI, constructed using a geometric mean as follows:

$$
s_{i}=\prod_{k=1}^{K} x_{i k}^{\delta_{k}}
$$

For $\beta>-1$, the elasticity of substitution is positive $(\sigma>0)$, which would be related with the rational preferences in the sense that averages are preferred to extremes. In the limit, when $\beta$ equals to infinity the components are viewed as perfect complements since $\sigma \rightarrow 0^{-}$. Then, for high positive values of $\beta$, only homogeneous achievements in all components would increase the level of well-being and the $s_{i}$ index is represented by the minimum value among the dimensions considered. In contrast, for $\beta<-1$, we have $\sigma<0$, which implies that extremes are preferred to averages. This assumption would lead corner solutions, in the sense that all efforts would be targeted to promote the dimension with better scores and, consequently, the other aspects of well-being will be completely disregarded. In the limit case $\beta=-\infty$, only the dimension with the best performance is considered in the assessment of well-being. ${ }^{3}$

In the second step, we study the inequality in the distribution of the index $s_{i}$. Following Maasoumi (1986, 1999), we use the class of indices of generalised entropy (GE). These inequality measures have been extensively used to perform inequality analysis in composite indicators of well-being, especially in the case of the HDI (see e.g., Ram (1992), McGillivray and Pillarisetti (2004), Pillarisetti (1997) and Martínez (2012)).

The GE inequality measures are given by,

$$
G E_{\gamma}(\mathbf{G})=\frac{1}{\gamma(1+\gamma)} \frac{1}{N} \sum_{i=1}^{N}\left[\left(\frac{s_{i}}{\bar{s}}\right)^{1+\gamma}-1\right], \quad \gamma \neq-1,0,
$$

where $\bar{s}$ is the arithmetic mean of the $s_{i}$ values, $N$ are the number of countries and $\gamma$ is a sensitivity parameter that weights more transfers at the right tail of the distribution as it increases. The limiting cases are given by $\gamma$ values equal to 0 (the same importance is attached to all parts of the distribution) and -1 (more weight is given to developing countries).

$$
\begin{aligned}
& G E_{-1}(\mathbf{G})=\frac{1}{N} \sum_{i=1}^{N} \log \left(\frac{\bar{s}}{s_{i}}\right), \\
& G E_{0}(\mathbf{G})=\frac{1}{N} \sum_{i=1}^{N} \frac{s_{i}}{\bar{s}} \log \left(\frac{s_{i}}{\bar{s}}\right) .
\end{aligned}
$$

This family comes from the theory of information, a fundament that contrasts with the normative approach of inequality. However, these measures are justified by a set of desirable axioms of information theory, which are similar to the desired axioms of the normative approach (Maasoumi, 1999; Lugo, 2007). ${ }^{4}$ Furthermore, this family includes a number of inequality measures such as the Theil index and the mean logarithmic deviation, and are ordinally equivalent (in the unidimensional case) to the coefficient of 
variation $(\gamma=1)$ and the Atkinson family of inequality measures (for $\gamma<0$ ) (Shorrocks, 1980; Maasoumi, 1986).

As can be concluded from the previous formulation, we take countries as units of analysis. According to Milanovic (2005), this kind of inequality is called Concept I or unweighted inequality. This type of inequality can be considered non-representative since countries such as China or India are given the same importance as low populated countries. Conversely, weighted inequality (or concept II of inequality) gives different weights to each country in terms of its population size. The adequacy of these two approaches depends on the focus of the analysis. Note that Concept II studies inequality between individuals. ${ }^{5}$ This study focuses on assessing the evolution of the gap between developing and developed countries and hence Concept I is more suitable in this case. Moreover, the non-income components of the HDI are strongly affected by the social policies, which are implemented at national level (Ravallion, 2004; Decancq et al., 2009).

\section{Data and results}

The data on the three components of the HDI come from Human Development Indicators (UNDP, 2012). ${ }^{6}$ Our sample comprises 122 countries over the period 1980-2011. For the period 1980-2005, we have 5-years intervals, whereas from 2005 to 2011 the data have annual frequency. We had non-available data for 16 countries in few years before 1995 . To not restricting the sample considerably, these missing values have been estimated. ${ }^{7}$ After this procedure, our sample covers the $86 \%$ of global population. ${ }^{8}$

This analysis begins with the graphical investigation of the cross-country distribution of well-being. As is usual in the literature, non-parametric estimation techniques are considered. This methodology avoids the need to decide ex-ante the functional form of the distribution of $s_{i}$, letting the data to state by themselves the shape of the distribution.

Figure 1 presents the evolution of the distribution of $s_{i}$ assuming different values for the $\beta$ parameter. The estimates are computed using a Gaussian kernel with optimal bandwidth (Silverman, 1986). The horizontal axis represents the country level of welfare and the vertical axis refers to the associated density. Particularly, we compute the $s_{i}$ index defined in (1) for $\beta$ equal to -1 and 0 , which corresponds, respectively, to the old and the new definition of the HDI. We also consider perfect complementarity $(\beta=\infty)$ and an intermediate case given by $\beta=10$.

Figure 1 points out that the evolution of cross-country distributions of well-being differs depending on the $\beta$ parameter. At the beginning of the study period, all indices presented a similar distribution with a main mode around 0.6. In 2011, a bimodal pattern is more appreciable for high rates of substitution, while it is less marked when dimensions are treated as perfect complements. The intermediate case characterised by $\beta=10$ shows a three-mode distribution. On the other hand, the distributions of the old HDI and its new version exhibit the same shape, thus implying that the changes applied to this indicator in 2010 have not strongly affected its distribution. In any case, there seems to be two groups of countries, being the cluster placed at the left tail made up basically of Sub-Saharan African economies, which are not able to overcome the human development barriers in health and income (Mayer-Foulkes, 2003).

While the cross-country distribution exhibits different shapes depending on the value of the $\beta$ parameter, the ranking of the countries seems to be rather invariant. In fact, the Spearman correlation rank shows values higher than 0.9 for the pairs of $s_{i}$ distributions 
shown in Figure 1. ${ }^{9}$ However, there are countries whose position differs notably according to different degrees of substitution. Cuba is the most prominent example. It is ranked as the 40th country according the old HDI classification $(\beta=0)$, while for the extreme case $(\beta=\infty)$, when only the worst dimensions count for the construction of the index, it is ranked in the 71 position. Wide differences in the positions of the countries are not exclusive of developing nations. A similar example is characterised by the 5 th most developed country according to the UNDP (2012): New Zealand. Assuming perfect complementarity relegates this country to the 25 th position owing to its comparative low performance in income with respect to other components.

Figure 1 Cross-country distribution of well-being assuming different substitutability rates. Solid lines represent the distribution in 1980 and dashed lines in 2011

$\beta=0$

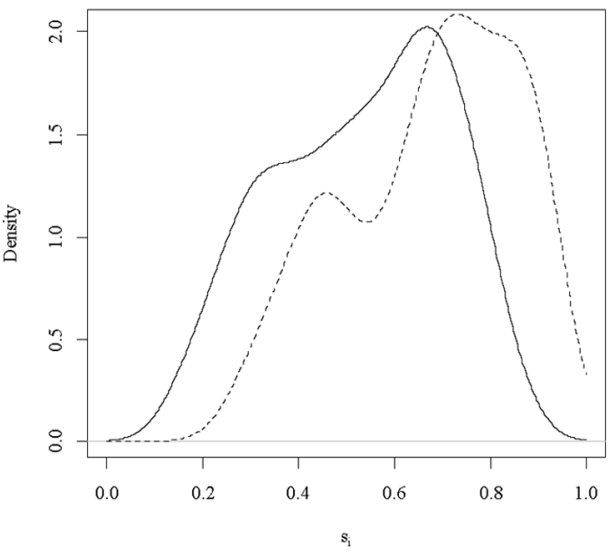

$\beta=10$

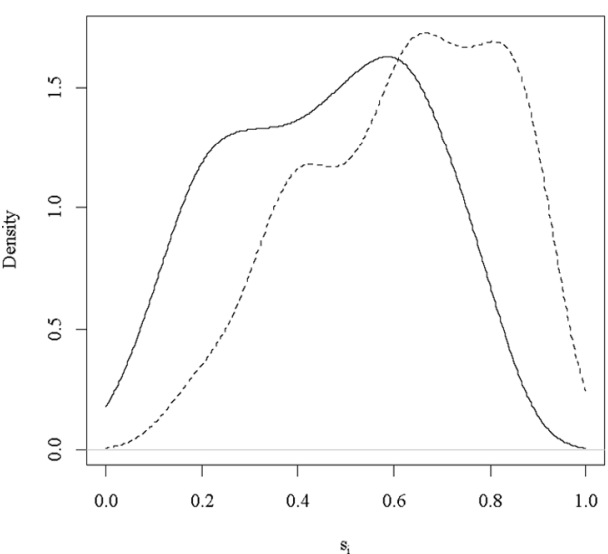

$\beta=-1$

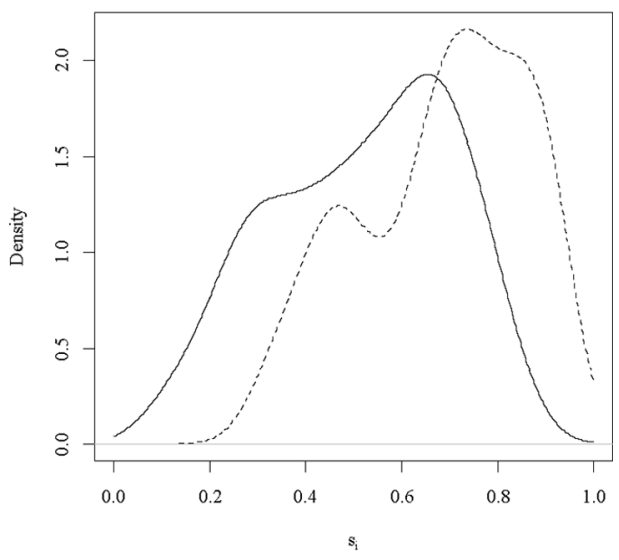

$\beta=\infty$

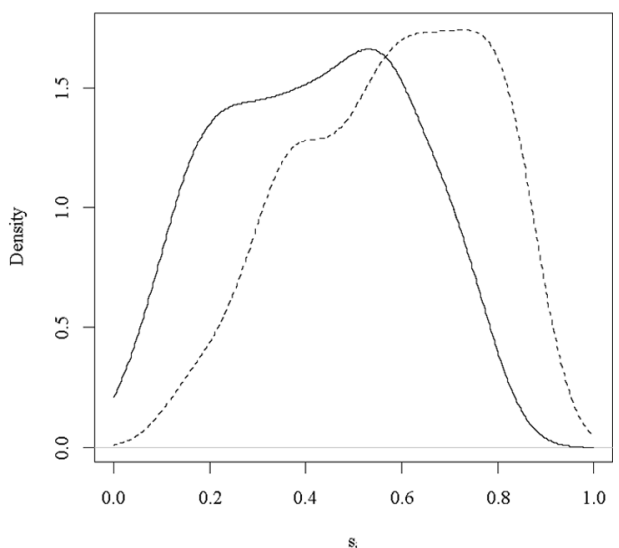

To quantify the changes in the dispersion of well-being distribution over the last three decades, we start analysing the evolution of inequality in each dimension independently. Table 1 includes the values of the Theil index for the components of the HDI. The last column presents the growth rate of unweighted inequality over the study period, which is called the rate of convergence (O'Leary, 2001). ${ }^{10}$ We observe that all the components of 
the HDI have seen a process of convergence during the last three decades. Educational outcomes present the highest decrease in cross-country disparities owing to the advances of Asian countries (Morrison and Murtin, 2012) and the promotion of primary education by Millennium Development Goals (Jordá and Sarabia, 2014). The decrease in inequalities in health is remarkably lower, owing to the divergence observed during the 1990s. The upward trend in unweighted health inequality is driven by the expansion of AIDS in Sub-Saharan Africa (Neumayer, 2003) and the erosion of life expectancy in Eastern European countries owing to social upheaval and tobacco and alcohol consumption (Moser et al., 2005). The income component of the HDI shows the lowest decrease in disparities owing to the well-documented fact of divergence during the second half of the century (see, e.g., Milanovic (2005)). The last 10 years, in contrast, seem to be characterised by a decrease in the economic gap between poor and rich countries.

Table 1 Evolution of unidimensional inequality in income, health and education

\begin{tabular}{lcccccccc}
\hline & 1980 & 1985 & 1990 & 1995 & 2000 & 2005 & 2011 & Growth rate \\
\hline Income & 0.0623 & 0.0605 & 0.0618 & 0.0648 & 0.0658 & 0.0616 & 0.0548 & -0.1204 \\
Health & 0.0296 & 0.0267 & 0.0281 & 0.0301 & 0.0296 & 0.0275 & 0.0216 & -0.2700 \\
Education & 0.1183 & 0.0989 & 0.0883 & 0.0786 & 0.0702 & 0.0578 & 0.0499 & -0.5779 \\
\hline
\end{tabular}

To provide overall conclusions regarding well-being inequality, we compute the multidimensional GE measures to the components of the HDI. ${ }^{11}$ Then, the distribution matrix is made up of the three dimensions, which are standardised variables as described in Section 2. Even when the standardisation formula affects the level of inequality, we do not perform a detailed sensitivity analysis for different standardisation procedures. However, we consider the effect of the logarithmic transformation on multidimensional inequality, which seems to play a crucial role in the assessment of disparities (Decancq et al., 2009). Two additional decisions have to be made to compute the $s_{i}$ index in the first step: the weighting scheme and the assumed degree of substitution. The rest of this section focuses on the effect of these choices on the evolution of well-being disparities.

As a starting point, we study the time trend evolution of well-being disparities according to the different degrees of substitution. Figure 2 presents well-being inequality during the period 1980-2011 with and without applying the logarithmic transformation to income. ${ }^{12}$ To facilitate the comparison of results, GE values have been normalised to be 100 in 1980. If the logarithmic transformation is applied to income, the greatest falls are observed when a high degree of complementarity is assumed across dimensions. In this case, a continuously decreasing trend of well-being inequality is observed. In contrast, assuming a high degree of substitutability among dimensions shows a different evolution over time. Global disparities in well-being fell unambiguously until the middle of the 1980s. This trend was followed by a decade of stagnation or slight decrease in global well-being inequality when considering the last version and the new definition of the HDI $(\beta=-1$ and $\beta=0)$, respectively. The last 15 years are characterised as a period of convergence. A completely different picture is observed if we do not apply the logarithmic transformation to income. In all cases but perfect substitution, an inverted U-pattern is observed, which shows a turning point in 2000. Under this framework, high degrees of complementarity lead the lowest decrease in inequality. Notwithstanding 
the different evolutions, we find that the last 10 years were characterised by a strong decrease in inequality. This decade is, in fact, characterised as the period when almost all reduction in inequality took place, thus leading convergence in levels of quality of life.

Figure 2 Evolution of inequality in well-being (Theil index). Left panel applies the HDI standardisation. Right panel computes well-being without transforming income into logarithms
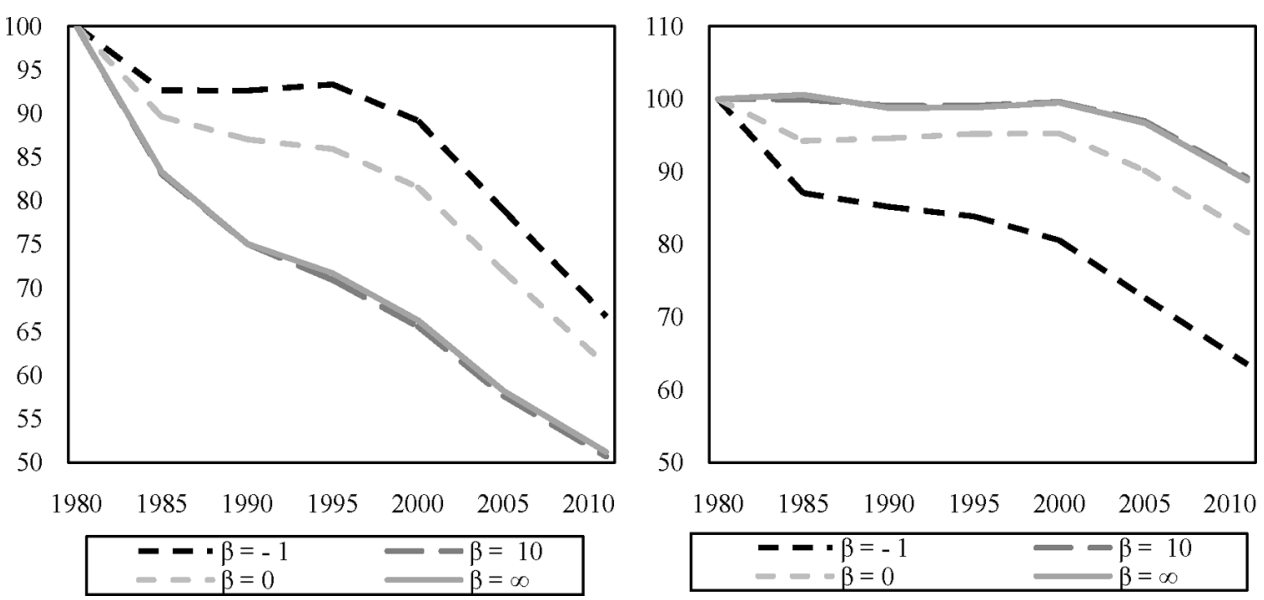

If we assume an equal weighting scheme and the standardised variables considered by HDI, GE measures in (2) can be seen as a function of two parameters: the assumed rate of substitution $(\beta)$ and the weight attached to the lower tail $(\gamma)$. The analysis of the entire evolution of disparities in well-being for a large number of combinations would require a large amount of space. Instead, we opt for presenting the growth rate of unweighted inequality over the period 1980-2011. Figure 3 presents the growth rate of the GE measures for different values of the $\beta$ parameter (horizontal axis) and $\gamma$ values (vertical axis). ${ }^{13}$ Note that the colour scale gives the combinations of the parameters that yield the same reduction of disparities.

Figure 3 Growth rate of unweighted inequality in well-being assuming different degrees of substitution (see online version for colours)

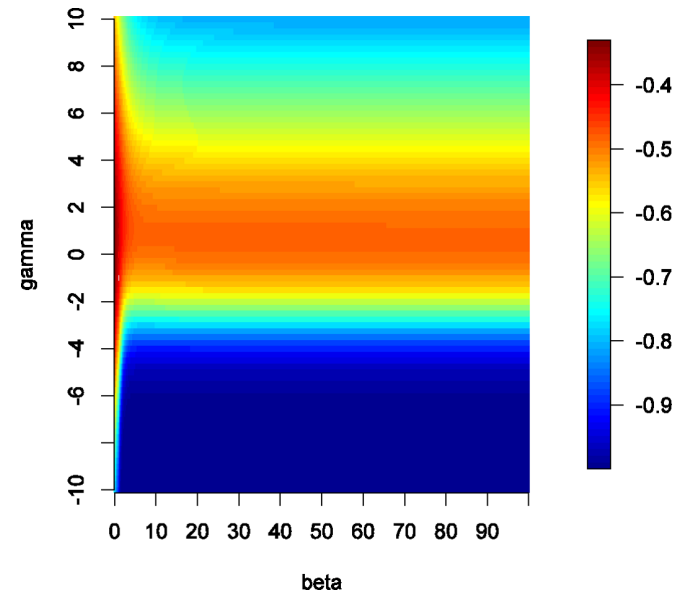


Our results point out that the lowest decrease in inequality is observed when all the countries equally weighted $(\gamma=0)$. If we weigh more developing countries $(\gamma>0)$, then the convergence rate decreases sharply. In fact, for values of the inequality aversion parameter lower than -4 , the fall of inequality is greater than 0.9 . Giving more weight to highly developed countries also yields a deeper fall of well-being inequality. However, the acceleration of the convergence rate is not as fast as the observed when the weight attached to poor nations increases. This analysis also suggests that the elasticity of substitution plays little role in the convergence rate. For parameter values higher than 10, the decrease in disparities remains unchanged for any given value of $\beta$. To analyse the influence of this parameter, we zoom into the part of Figure 5 that corresponds to $\beta<10$ and $\gamma>-5$ (Figure 4). ${ }^{14}$ The general pattern is that the higher the degree of substitution, the greater the decrease in inequality. However, the impact of this parameter on the reduction of disparities in well-being is practically null for $\beta$ values higher than 4 .

Figure 4 Growth rate of unweighted inequality in well-being for $\beta$ values lower than 10 (see online version for colours)

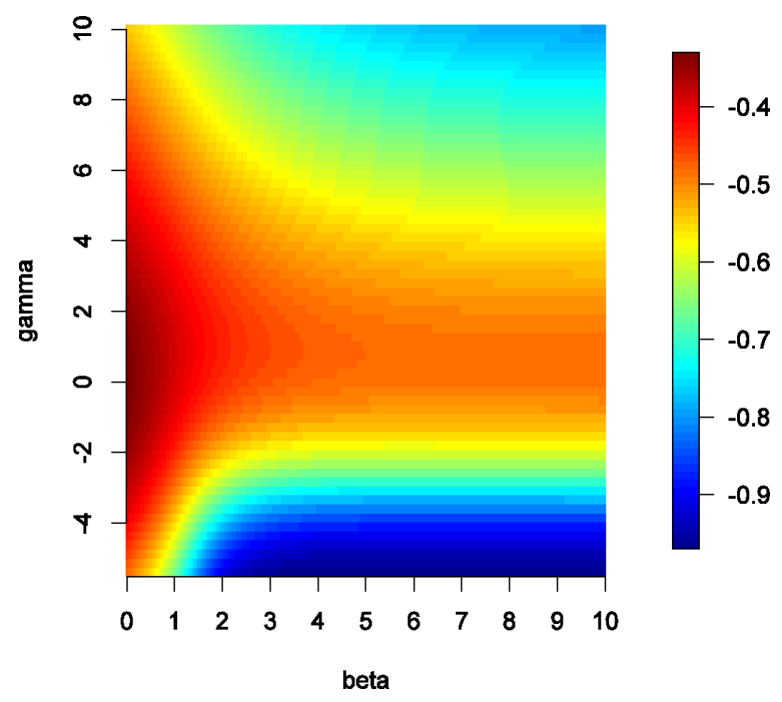

We focus now on the influence of the weighting structure on the evolution of the gap between developed and developing countries. Figure 5 presents the evolution of the Theil measure of the $s_{i}$ index for different weighting schemes. ${ }^{15} \mathrm{We}$ assume that the substitution parameter is equal to 0 , which corresponds to the new version HDI. This figure informs about the growth rate of well-being inequality as the weight of income (vertical axis) increases and as the weight of education increases (horizontal axis). ${ }^{16}$ Then, the corners of the triangle correspond to the growth rate of inequality presented in Table 1 . The point $(0,1)$ is associated with income inequality, $(0,0)$ with inequality in health and $(1,0)$ with inequality in education. The vertical axis shows the levels of inequality when no weight is given to education. The no consideration of education is based on the argument that educational variables only have instrumental value (Decancq, 2011) and their inclusion as an individual dimension would involve a double counting (Becker, 2007). On the other hand, the horizontal axis plots the growth rate of well-being disparities when only the non-economic variables are considered to assess levels of 
quality of life. These results would be associated with the inequality of the so-called nonincome HDI.

Our results suggest higher reductions of well-being inequality as greater weight is attached to education. Conversely, since the income component presents the lowest convergence rate, the higher its weight, the lowest the fall of well-being inequality. The colour legend shows again the combinations of weights that lead the same growth rate of inequality over the study period. We observe that, if the importance of education is low in comparison with the other two dimensions, the increase in income weight for a fixed increase in the education weight is constant. In contrast, for high values of the educational weight, these lines become concave.

Figure 5 Growth rate of unweighted inequality in well-being assuming different weighting schemes (see online version for colours)

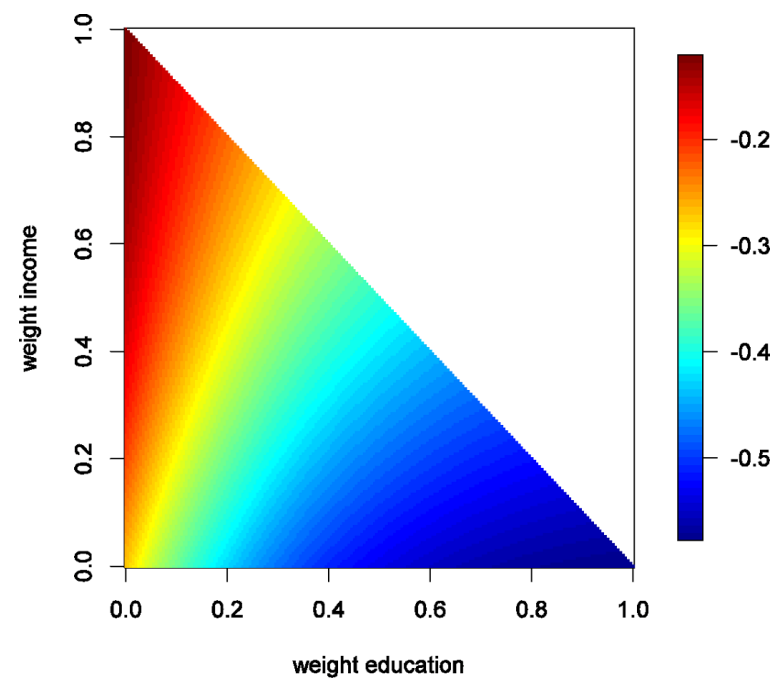

\section{Conclusions}

The consideration of income as a poor indicator to assess well-being has led several attempts to develop a more comprehensive indicator, which takes into account the multidimensional nature of quality of life. As a result, the hypothesis of convergence has been widely studied under a multi-attribute framework. While the general conclusion is the evidence of convergence over the last decades, there is no consensus about the intensity of this process. The differences may come from the different normative choices on the weights of the variables, its standardisation formula, the assumed substitution between dimensions as well as the aversion to inequality that is expected to represent the society values.

In this study, we have investigated the role of some of these choices in the evolution of well-being inequality using the two-step procedure proposed by Maasoumi (1986). We take the HDI as a theoretical framework, thus focusing on variables of income, health and education. The analysis of disparities over the last three decades suggests that the logarithmic transformation applied to income has a strong influence on the time trend evolution of unweighted inequality. On the other hand, the sensitivity analysis on weights 
reveals a decrease in well-being disparities for any weighting scheme given that all components have seen a process of convergence over the study period. In terms of the inequality aversion parameter, we find that the lowest rate of convergence is observed when all countries are equally weighted $(\gamma=0)$. As this parameter increases and decreases, the growth rate of the GE measures tends to be more pronounced. The acceleration of the convergence rate is especially intense as the weight attached to developing countries increases. Finally, the impact of the degree of substitution between dimensions on the rate of convergence seems to be limited for high degrees of complementarity.

Despite the differences in the evolution of inequality in well-being under different scenarios, our analysis reveals a robust general conclusion: levels of quality of life converged over the last three decades. This conclusion contrasts with the result obtained by Martínez (2012), who found opposite trends for the new and the old versions of the HDI. The different results presented by Martínez come from the use of absolute measures, which yields the same level of inequality if all incomes are increased by the same amount. Conversely, we have used relative inequality measures, which assume that the distribution would be equality unequal if we increase all incomes by the same proportion. The extension of this analysis using absolute or intermediate indicators might be an interesting line for future research.

\section{Acknowledgements}

The authors thank the Ministerio de Economía y Competitividad (Project ECO201015455) and the Ministerio de Educación (AP2010-4907) for partial support of this work. They are grateful for the constructive suggestions provided by the editor and the reviewers, which greatly improved the paper.

\section{References}

Alkire, S. (2002) 'Dimensions of human development', World Development, Vol. 30, pp.181-205.

Barro, R.J. and Lee, J.W. (2010) A New Data Set of Educational Attainment in the World, 1950-2010, NBER Working Paper 15902, National Bureau of Economic Research, Cambridge, MA.

Becker, G.S. (2007) 'Health as human capital: synthesis and extensions', Oxford Economic Papers, Vol. 59, pp.379-410.

Bosmans, K., Decancq, K. and Ooghe, E. (2013) What Do Normative Indices of Multidimensional Inequality Really Measure? (No. 2013035), Université Catholique de Louvain, CORE.

Chowdhury, S. and Squire, L. (2006) 'Setting weights for aggregate indices: an application to the commitment to development index and Human Development Index', Journal of Development Studies, Vol. 42, pp.761-771.

Decancq, K. (2011) 'Measuring global well-being inequality: A dimension-by-dimension or multidimensional approach?', Reflets et perspectives de la vie économique, Vol. 4, pp.179-196.

Decancq, K. and Lugo, M.A. (2013) 'Weights in multidimensional indices of wellbeing: an overview', Econometric Reviews, Vol. 32, pp.7-34.

Decancq, K., Decoster, A. and Schokkaert, E. (2009) 'Evolution of world inequality in well-being', World Development, Vol. 37, pp.11-25. 
Fritsch, F.N. and Carlson, R.E. (1980) 'Monotone piecewise cubic interpolation', SIAM Journal on Numerical Analysis, Vol. 17, pp.238-246.

Haq, M.U. (2003) 'The birth of the Human Development Index', In Fukuda-Parr, S. and Shiva Kuma, A.K. (Eds.): Readings in Human Development, Oxford University Press, Oxford, pp.127-137.

Hobin, B. and Franses, P.H. (2001) 'Are living standards converging?', Structural Change and Economics Dynamics, Vol. 12, pp.171-200.

International Monetary Fund (IMF) (2011) World Economic Outlook Database, April, Washington, DC.

Jerven, M. (2013) Poor Numbers: How We Are Misled by African Development Statistics and What to Do about It, Cornell University Press, Ithaca, NY.

Jordá, V. and Sarabia, J.M. (2014) 'International converge in well-being indicators', Social Indicators Research, in press.

Jordá, V., Trueba, C. and Sarabia, J.M. (2013) 'Assessing global inequality in well-being using generalized entropy measures', Procedia Economics and Finance, Vol. 5, pp.361-367.

Kenny, C. (2005). 'Why are we worried about income? Nearly everything that matters is converging', World Development, Vol. 33, pp.1-19.

Klugman, J., Rodríguez, F. and Choi, H-J. (2011) 'The HDI 2010: new controversies, old critiques', Journal of Economic Inequality, Vol. 9, pp.249-288.

Konya, L. and Guisan, M.C. (2008) 'What does the Human Development Index tell us about convergence?', Applied Econometrics and International Development, Vol. 8, pp.19-40.

Lugo, M.A. (2007) 'Comparing multidimensional indices of inequality: methods and application', Research on Economic Inequality, Vol. 14, pp.213-236.

Maasoumi, E. (1986) 'The measurement and decomposition of multidimensional inequality', Econometrica, Vol. 54, pp.991-997.

Maasoumi, E. (1999) 'Multidimensional approaches to welfare analysis', Handbook of Income Inequality Measurement. Springer, Netherlands, pp.437-484.

Maasoumi, E. and Nickelsburg, G. (1988) 'Multivariate measures of well-being and an analysis of inequality in the Michigan data', Journal of Business \& Economic Statistics, Vol. 6, pp.327-334.

Martínez, R. (2012) 'Inequality and the new Human Development Index', Applied Economics Letters, Vol. 19, pp.533-535.

Mayer-Foulkes, D. (2003) 'Convergence clubs in cross-country life expectancy dynamics', in van der Hoeven, R. and Shorrocks, A. (Eds.): Perspectives on Growth and Poverty, United Nations University Press, Tokyo, pp.144-171.

McGillivray, M. and Markova, N. (2010) 'Global inequality in wellbeing dimensions', Journal of Development Studies, Vol. 46, pp.371-378.

McGillivray, M. and Pillarisetti, J.R. (2004) 'International inequality in well-being', Journal of International Development, Vol. 16, pp.563-574.

Milanovic, B. (2005) Worlds Apart: Measuring International and Global Inequality, Princeton University Press, Princeton and Oxford.

Morrison, C. and Murtin, F. (2012) 'The Kuznets curve of human capital inequality: 1870-2012', Journal of Economic Inequality, Vol. 11, pp.283-301.

Moser, K., Shkolnikov, V. and Leon, D.A. (2005) 'World mortality 1950-2000: divergence replaces convergence from the late 1980s', Bulletin of the World Health Organization, Vol. 83, pp.202-209.

Neumayer, E. (2003) 'Beyond income: convergence in living standards, big time', Structural Change and Economic Dynamics, Vol. 14, pp.275-296.

Nguefack-Tsague, G., Klasen, S. and Zucchini, W. (2011) 'On weighting the components of the Human Development Index: a statistical justification', Journal of Human Development and Capabilities, Vol. 12, pp.183-202. 
O'Leary, E. (2001) 'Convergence of living standards among Irish regions: the roles of productivity, profit outflows and demography, 1960-1996', Regional Studies, Vol. 35, pp.197-205.

Pillarisetti, J.R. (1997) 'An empirical note on inequality in the world development indicators', Applied Economic Letters, Vol. 4, pp.145-147.

Ram, R. (1992) 'International inequalities in human development and real income', Economics Letters, Vol. 38, pp.351-354.

Ravallion, M. (2004) 'Competing concepts of inequality in the globalization debate', in Collins, S. and Graham, C. (Eds.): Bookings Trade Forum 2004, Brookings Institution.

Ravallion, M. (2012) 'Troubling tradeoffs in the Human Development Index', Journal of Development Economics, Vol. 99, pp.201-209.

Sen, A. (1988) 'The concept of development', in Chenery, H. and Srinivasan, T.N. (Eds.): Handbook of Development Economics, Elsevier, Amsterdam, pp.9-26.

Sen, A. (1989) 'Development as capabilities expansion', Journal of Development Planning, Vol. 19, pp.41-58.

Sen, A. (1999) Development as Freedom, Oxford University Press, Oxford.

Shorrocks, A.F. (1980) 'The class of additively decomposable inequality measures', Econometrica: Journal of the Econometric Society, Vol. 48, pp.613-625.

Silverman, B.W. (1986) Density Estimation for Statistics and Data Analysis, Chapman and Hall, London.

UNDP (1990) Human Development Report 1990: Concept and Measurement of Human Development, Oxford University Press, New York.

UNDP (2010) Human Development Report 2010: The Real Wealth of Nations: Pathways to Human Development, Oxford University Press, New York.

UNDP (2012) International Human Development Indicators, Retrieved from http://hdr.undp.org/ en/statistics/ (Accessed on 28 March, 2013).

United Nations Department for Economic and Social Affairs (UNDESA) (2011) World Population Prospects: The 2010 Revision, CD-ROM Edition, United Nations, New York.

United Nations Educational, Scientific and Cultural Organization (UNESCO) (2011) UNESCO Institute for Statistics, Data Centre.

United Nations Statistics Division (UNSD) (2011) National Accounts Main Aggregates Database, New York, http://unstats.un.org/unsd/snaama/

Weymark, J.A. (2006) 'The normative approach to the measurement of multidimensional inequality', in Farina, F. and Savaglio, E. (Eds.): Inequality and Economic Integration, Routledge, London, pp.303-328.

World Bank (2011) Global Economic Prospects - June 2011, Washington, DC.

\section{Notes}

${ }^{1}$ See Decancq et al. (2009) and Decancq (2011) for sensitivity analyses of the evolution of multidimensional inequality using axiomatic measures. These studies measure both components of multidimensional inequality (equity and efficiency) and hence their results are not comparable with this analysis.

${ }^{2}$ According to Ravallion (2012), the new structure of the HDI hides problematic trade-off between the core dimensions and the value of the index. The misleading trade-offs are more prominent in terms of life expectancy, in the sense that the new version of the HDI devaluates life expectancy in developing countries.

${ }^{3}$ It is clear that this scenario is not in concordance with the theoretical framework of human development. Then, even when Maasoumi's approach can be computed for any value of the $\beta$ parameter, we restrict the analysis to values higher than -1 . 
${ }^{4}$ See Lugo (2007) for a review of the properties of the two-step procedure using GE measures.

${ }^{5}$ Concept II of inequality assumes that all the citizens in a particular country have the same level of income (the per-capita income level), thus ignoring inequality within the country. Then, some extent of disparities is not assessed using that concept and it is seen as a lower bound of inequality levels. Ideally, the specific situation of each individual should be taken into account to evaluate inequality levels (concept III), but individual data on non-income dimensions is not available for several countries.

${ }^{6}$ See Appendix B for information on the sources of the UNDP data.

${ }^{7}$ See Appendix A for details on the interpolation technique and the countries included in the dataset.

${ }^{8}$ Given that most absentees are developing countries, our results may be biased downward. Another source of bias might be low reliability of the national accounts reported by African countries (see Jerven, 2013).

${ }^{9}$ Spearman rank correlations are computed for the year 2011. These results are available upon request.

${ }^{10}$ Strictly speaking, O'Leary (2001) defined the rate of $\sigma$-convergence as the growth rate of the coefficient of variation. We use the abbreviated term rate of convergence to refer the growth rate of the GE measures.

${ }^{11} \mathrm{We}$ are implicitly assuming that well-being is adequately represented by the dimensions included in the HDI. However, other components have been proposed as relevant candidates to represent quality of life (see Alkire, 2002) for a review on this topic). We restrict ourselves to the framework provided by the HDI, thus not analysing the robustness of the results to the consideration of other dimensions of well-being.

${ }^{12}$ These results have also been computed without including the interpolated values, using a sample of 106 countries. The evolution of unweighted inequality in well-being was the same as the trends presented in Figure 2. The maximum difference was quantified by $2 \%$ and 0.002 in relative and absolute terms, respectively. These results are available from authors upon request.

${ }^{13}$ Parameter $\beta$ varies from 0 to 100 by increments of 0.25 while the inequality aversion parameter varies from -10 to 10 by steps of 0.25 . Then, we present the growth rate of inequality for 32,481 combinations of $\beta$ and $\gamma$ parameters.

${ }^{14}$ Parameter $\beta$ varies from 0 to 10 by steps of 0.02 and the inequality aversion parameter varies from -5 to 10 by steps of 0.25 . Therefore, Figure 4 presents the growth rate of inequality for 17,081 combinations of the $\beta$ and $\gamma$ parameters.

${ }^{15}$ Figure 5 includes 20,301 combinations of weights obtained by increasing the weight value of each dimension by steps of 0.005 .

${ }^{16}$ As the weights are restricted to sum to 1 , the weight of health is determined by $w_{h}=1-w_{y}-w_{e}$.

\section{Appendix A: Countries included in the analysis}

\begin{tabular}{lll}
\hline $\begin{array}{l}\text { Afghanistan } \\
\text { Albania }^{\mathrm{b}^{*}}\end{array}$ & Greece & Nicaragua \\
Algeria & Guatemala & Niger \\
Argentina & Guyana & Norway \\
Australia & Haiti & Pakistan \\
Austria & Qatar & Panama \\
Bahrain & Honduras & Papua New Guinea \\
Bangladesh & Hong Kong, China (SAR) & Paraguay \\
Belgium & Hungary & Peru \\
\hline
\end{tabular}


Appendix A: Countries included in the analysis (continued)

\begin{tabular}{|c|c|c|}
\hline Belize & India & Poland $^{\mathrm{c}}$ \\
\hline Benin & Indonesia & Portugal \\
\hline Bolivia (Plurinational State of) & Iran (Islamic Republic of) & Rwanda \\
\hline Botswana & Ireland & Saudi Arabia \\
\hline Brazil & Israel & Senegal \\
\hline Brunei Darussalam & Italy & Sierra Leone \\
\hline Bulgaria $^{a}$ & Jamaica & South Africa \\
\hline Burundi & Japan & Spain \\
\hline Cameroon & Jordan & Sri Lanka \\
\hline Canada & Kenya & Sudan \\
\hline Central African Republic & Korea (Republic of) & Swaziland \\
\hline Chile & Kuwait & Sweden \\
\hline China & Lao People's Democratic Rep. ${ }^{b}$ & Switzerland $^{\mathrm{b}}$ \\
\hline Colombia & Latvia $^{\mathrm{b}^{*}}$ & Syrian Arab Republic \\
\hline Congo & Lesotho & Tanzania (United Republic of) ${ }^{b^{*}}$ \\
\hline Congo (Democratic Republic) & Liberia $^{\mathrm{d}}$ & Thailand \\
\hline Costa Rica & Luxembourg & Togo \\
\hline Côte d'Ivoire & Malawi & Tonga \\
\hline $\mathrm{Cuba}^{\mathrm{a}}$ & Malaysia & Trinidad and Tobago \\
\hline Cyprus $^{\text {a }}$ & Mali & Tunisia \\
\hline Denmark & Malta & Turkey \\
\hline Dominican Republic & Mauritania & Uganda $^{\mathrm{a}}$ \\
\hline Ecuador & Mauritius & UAE \\
\hline Egypt & Mexico & UK \\
\hline El Salvador & Mongolia $^{\mathrm{a}}$ & USA \\
\hline Fiji & Morocco & Uruguay \\
\hline Finland & Mozambique $^{\mathrm{a}}$ & Venezuela (Bolivarian Republic) \\
\hline France & Myanmar & Viet $\mathrm{Nam}^{\mathrm{b}}$ \\
\hline Gabon & Namibia $^{a}$ & Yemen $^{\mathrm{c}}$ \\
\hline Gambia & Nepal & Zambia \\
\hline Germany & Netherlands & Zimbabwe \\
\hline Ghana & New Zealand & \\
\hline
\end{tabular}

${ }^{\mathrm{a}}$ Estimated income in $1980,{ }^{\mathrm{b}}$ Estimated income in $1980,1985,{ }^{\mathrm{c}}$ Estimated income in 1980, 1985, 1990, ' Estimated income in 1990, 1995. *Average growth rate used for interpolation.

The sample without interpolated values comprised 106 countries, which represented the $82 \%$ of global population. All the missing observations are income data previous to 1995 . The estimation of missing values is based on two complementary methodologies, which provide feasible and consistent results according to the sample. In a first step, we use the piecewise cubic Hermite interpolating polynomial. The interpolated values have been 
obtained using the command pchip of the R package Signal, which uses the methodology described by Fritsch and Carlson (1980). In the case where this method offers unfeasible estimates, the average rate of change is used. After the implementation of these techniques, our dataset includes 122 countries whose indicators of income, health and education are available over the whole study period, thus covering by $86 \%$ of the world population.

\section{Appendix B: UNDP sources}

- Life expectancy at birth: UNDESA (2011).

- Mean years of schooling: HDRO updates (http://hdr.undp.org/en/statistics/) based on UNESCO data on education attainment (http://stats.uis.unesco.org/unesco) using the methodology outlined in Barro and Lee (2010).

- Expected years of schooling: UNESCO Institute for Statistics (2011).

- GNI per capita: World Bank (2011), IMF (2011), UNSD (2011). 